\title{
OCCUPATIONAL HEALTH AND SAFETY (OHS) MANAGEMENT VIS- À-VIS DIFFERENT PHASES OF CONSTRUCTION ACTIVITIES
}

\author{
G.V.R.Srinivasa Rao ${ }^{1}$, Viswanadham. Silaparasetti ${ }^{2 *}$, Y.Abbulu ${ }^{3}$ \\ ${ }^{1,3}$ Professor, Department of Civil Engineering, College of Engineering (A), Andhra University, Visakhapatnam, \\ Andhra Pradesh, India \\ ${ }^{2 *}$ Research Scholar, Department of Civil Engineering, College of Engineering (A), Andhra University, Visakhapatnam, \\ Andhra Pradesh, India (Corresponding Author)
}

\begin{abstract}
Accidents at construction sites are identified as a major problem throughout the world. Apart from the accidents at construction sites, people working in the construction industry suffer from several occupational health disorders. In this backdrop, implementation of an effective occupational health and safety measures are gaining importance these days across the world. In line with this discussion, the present paper aims at assessment of occupational health and safety management w.r.t. different phases of construction activates i.e. pre-construction, construction and post-construction phases. It is observed that, the concept of occupational health and safety is not only applicable construction phase but also equally applicable to both pre-construction and post-construction.
\end{abstract}

Key Words: Occupational health, safety, accidents, construction phase, pre-construction phase, post- construction phase, safety culture, safety assessment.

\section{INTRODUCTION}

Globally, construction activities account for $13.4 \%$ of market share of world's economy worth US\$ 7.5 trillion. By 2020 , it is estimated that construction sector will grow by $70 \%$ i.e. to US\$ 12.7 trillion accounting to $14.6 \%$ of world economy [23].

Construction industry is labor intensive and employs a good number of skilled, semi-skilled and un-skilled laborers. One of the major problems the construction industry is facing these days is accidents at the construction sites. As per one report approximately 55,000 accidents leading to death occur globally per annum [44]. Apart from these accidents, significant portion of work force working at the construction sites is suffering from occupational health related problems.

The accidents in the construction sites are due to unsafe conditions, practices, procedures, actions and the lack of Occupational Health and Safety policies (OH\&S), inadequate training, improper inspection standards, etc. These accidents result in both fatalities of workforce and the large scale property damages which result in short and long term after effects to the organization, community and the country [1].

These large scale damages can be prevented with an effective implementation of occupational health and safety management (OH\&SM) principles at different phases of construction activities. However, the application of these principles at different phases of construction varies in principle and content. Therefore, it is aimed in the present paper to assess the application of OH\&SM policies for different phases of construction industry.

\section{Phases of construction:}

Construction activity can be divided into three phases, Preconstruction, Construction and Post-construction. Participants in construction industry are client/owner, consultants, engineers and contractors. Fig1 gives a detailed account of activities related to the above cited different phases of construction. The relations that exist among the stakeholders of construction w.r.t. the maintenance of $\mathrm{OH} \& \mathrm{~S}$ policies are shown in Fig 2.

\subsection{Pre-construction phase}

The pre-construction phase involves activities like planning at inception, feasibility, design, tendering, procurement and to plan the project completely in a standardized and efficient manner to ensure that the necessary government approvals, land, tools, materials, equipment and labour will be available to complete the project on time and within the budget. Also, it involves setting up of the systems that are needed to manage the project efficiently, such as procurement of materials, delivery and storage, scheduling and tracking, change management, and numerous other processes that are necessary to manage the project successfully.

\subsection{Construction phase}

The construction phase comprises of many activities and specialized services with cost, time, quality and safety being important of all [1]. The main activities in construction phase are planning, execution and commissioning. Selection 
and planning needs to be exercised very seriously as it is one of the factors that affect the progress of work [48]. In executing a project the key elements of OH\&SM such as health and safety policies, risks, organizing, planning, implementing, monitoring, reviewing and auditing of these policies do have vital role.

\subsection{Post-construction phase}

After the construction is completed, post construction activities like commissioning, testing, functional performance tests will be conducted by the contractor, leading to the continuance of association of contactor and the client.

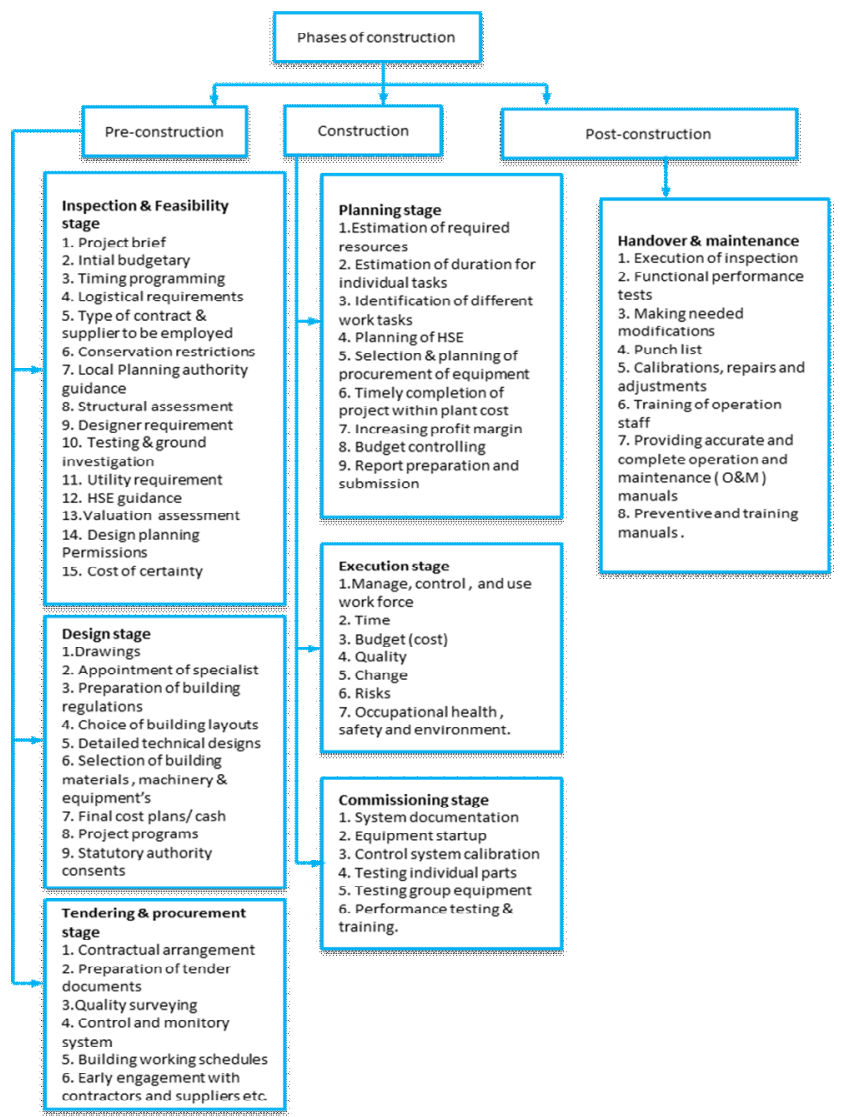

Figure 1: Construction phases and Activities

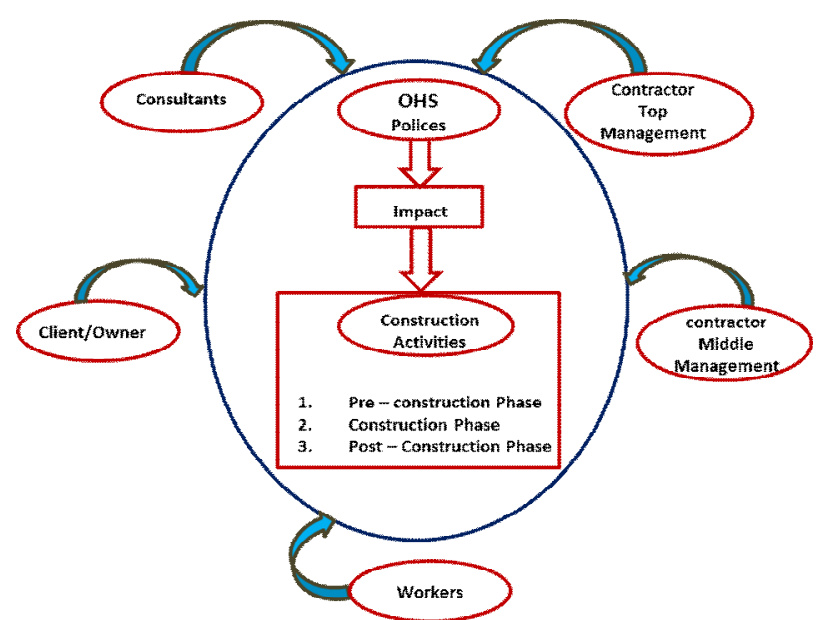

Figure 2: Various stakeholders in the maintenance of $\mathrm{OH} \& \mathrm{~S}$ policies in Construction Activities

\section{Assessment of OH\&S concept w.r.t Pre-}

\section{Construction phase}

Promotion of Occupational Health and safety $(\mathrm{OH} \& \mathrm{~S})$ in the Pre-constructional activities like inception and feasibility, design and procurement, is becoming a necessity in the present day construction activities. Clint/Owner needs to consider the importance of health and safety during the feasibility, design, and tendering phases itself. Project Managers need to refer to $H \& S$ during the design and construction phases, along with the perceived risk management [37].

A study on history of construction safety identified that good number of accidents occurred due to the design failure. Therefore, improved engineering design is much sought after concept adopted by today's construction industry for reduction of occupational health and safety risks [66]. Addressing safety in the design phase during preconstruction stage may eliminate or reduce the hazards in the construction phase [73]. Engineers and architects need to use their experience, training and knowledge in the design stage to eliminate the risks and ensure that the risks do not reach the construction site [46]. Designer safety education and training is identified as the $\mathrm{OSH}$ element during preconstruction stage. The necessary information is to be provided to the design team related to the mandatory $\mathrm{OH} \& \mathrm{~S}$ policies to be implemented in the design stage itself which would assist the designer team to understand the drives of the project. Feedback and lessons learned needs to be communicated to the designer for further improvements for the upcoming projects [42].

Accidents marginalize the overall project performance. Quality management systems (QMS) ensure adherence of quality standards for the construction. Inferior design can result in a poor $H \& S$ culture and marginalization of both $\mathrm{H} \& \mathrm{~S}$ and overall project performance [38].

Construction Hazards Prevention through Design (CHPtD) is one such policy with different aspects like the designs that facilitate prefabricated construction components, selection of material and proven construction technology for preventing construction risks and ensuring the safety norms and implementation in engineering - procurement construction industry (EPC) [45] can help in effectively planning the pre-constructional activities.

In tendering stage itself, there is a need to develop a framework directive for the implementation of strong health and safety requirements and government legislations at construction sites by contractors, sub-contractors and equipment suppliers. With the legislation implemented in its true spirit by the European countries and by concentrating on prevention through design in the construction industry, the incident rate has found to be decreased considerably [18].

\section{Assessment of OH\&S concept w.r.t Construction} phase 
In the construction stage the main stakeholder influences the policy implementation and approach which later indirectly effects on the Partnership, Strategy, Method, Resources, Safety Policies, Project duration and Process [67].

Assessment of $\mathrm{OH} \& \mathrm{~S}$ concepts w.r.t. specific aspects related to construction phases like hazards and risk, safety culture and climate etc. are presented in the following text.

\subsection{Assessment of OH\&S concept w.r.t Hazards and Risk}

In construction industry hazards mean potential for accident or incident leading to injuries or disabilities. Construction hazards are of physical, biological, ergonomic, chemical and psychological nature and can be identified by job safety analysis, task observation, work place inspection, combined techniques, accidents, and ill health or near miss data. Control measures can be of medical, engineering and administrative /legal domains.

Risk factor is product of probability and severity. Risk assessment involves identification of the hazards, evaluation of risks and existing precautions, deciding who may be harmed and how, recording the findings and reviewing the assessments. Lack of Risk perception and analysis, and nonadherence to safety norms lead to risk exposures for the workmen and people in the vicinity of the construction site resulting in occurrence of incidents and accidents [1].

The present day construction industry is aware of management approaches dealing with hazards. The identification of hazards and managing risks form an integral part towards continually improving safety levels in infrastructure management. Decision support tools are required to improve the safety of workers by facilitating hazards identification and management of associated control measures [32].

A qualitative occupational risk assessment (QRAM) model can be developed using the possibility and severity factors of work accidents along with barriers to safety [54]. The contribution of construction project features (CPFs) to accident causation and health and safety risk can as well be utilized to develop risk matrix for the construction industry [52]. However, the occupational risk assessment matrix needs to be implemented in accordance with local regulations [62].

\subsection{Assessment of $\mathrm{OH} \& S$ concept w.r.t Safety}

\section{Culture and Climate:}

The safety culture of any industry is the outcome of collective values like approach towards safety, capabilities of the workmen, industry's commitment towards safety and higher management's involvement in promoting the health $\&$ safety culture, by the means of educating and training the employees.
Safety climate and safety culture over the years has gained attention significantly and receiving the utmost priority in the industrial environment. Safety culture is being given prime consideration in model construction process and became a part of organizational structure of a project. Safety issues are duly addressed in projects, complicated site situations and environments. Thus, the safety culture as a concept is elaborately assimilated in overall framework of a project [20], these days. Safety Culture is directly proportional to the project performance. The safer the execution is the better is the result and vice a versa [47]. A specific tool kit suiting the industry type can be developed for safety climate and culture maturity improvement [61].

The association between advice and performance is highlighted in a study on practice of OS\&H and on the relationship between safety culture and actual performance. There is a need to consider OS\&H advice to investigate the relation between safety culture and performance [74].

Financial and humanitarian benefits pre-dominate the positive impact of health and safety culture on health and safety performance. The improved performance and productivity is the prominent collective benefit due to the implementation of the H\&S policies. These balanced benefits counter the notion that ' $\mathrm{H} \& \mathrm{~S}$ cost money' [63].

The actions of prominent stakeholders in the industry like focusing on factors like risk perception, and methods of prevention of hazards can help in improving the Safety culture to a great extent [55].

Studies on Safety culture and Risk perception conducted on company managers and owners revealed that the Managers reviewed the perception of Risk and Safety culture at higher levels than the workers. Managers also were found far more committed to Safety and health when compared to the workers [17]. Cultural issues on workers and Managers also were examined and found to vary [51].

There exists a very dynamic and interactive relation between all the stakeholders of the construction projects w.r.t safety culture. There exists a strong relationship between project safety and health performance with the owner involvement [72]. For smaller contracts improvements on safety culture at various levels can be case specific depending upon the size of the organization, safety maturity and type of work and available resources [65].

The safety culture constitutes of the following : perception and behavior each stakeholder, workers' perception and safety related behavior, work environment and management's perception and safety related behavior, and environment. Tools developed for the measurement of each of the constituents of Safety culture give the idea of the status of each of these aspects of safety for the construction Project / Industry [20].

Safety effectiveness can be measured using Safety Effectiveness indicators that are accepted by present day 
construction industry [6]. General awareness and knowledge about particular reasons on the root of accidents is necessary to undertake optimal measures at every stage of safety management [70]. Crosswalk between social network analysis and safety knowledge is desired to examine relationship between communication channels and dissemination of safety methods is very useful in developing suitable models in this regard [5].

\subsection{Assessment of $\mathrm{OH \& S}$ concept w.r.t Safety}

\section{framework and Bench marks.}

Items such as fixed barricades, hand railings, guardings, covers on open areas, strong roofing and planks/boards for crawling would form a basic or primary safety frame work. Fall arresting and containment systems such as safety belts, safety harness, safety nets can be included in the safety frame work as secondary measures of protection. [11]. It is very important to identify all potential safety hazards of construction projects during initiation itself so that social and financial costs are minimized. The safety performance and evaluation of (SPE) factors can assist contractors to identify all such hazards [71]. Interaction between IT, Knowledge Management principles and $\mathrm{OH} \& \mathrm{~S}$ principles provide excellent stage for framing a concrete framework with a web based Management system for $\mathrm{OH} \& \mathrm{~S}$ for different enterprises. [30]. Competent personnel for the maintenance of health and safety in construction industries can be selected through the tools developed by Knowledge Based System (KBS) [24]. Small and medium sized Enterprises (SMEs) face a lot of limitations in effective management of $\mathrm{OH} \& \mathrm{~S}$. Some of the factors affecting the performance are inadequate literacy levels, low economic and social capabilities of managers and owners, family commitments and obligations, incompetent administration of $\mathrm{OH} \& \mathrm{~S}$, etc. [49].

Development and improvement of Safety culture in the construction sites [25], prevention of accidents like falling from height by imparting training to workers [28] are some of the initiatives to improve safety performance through proper frameworks in construction industries and bench marking [39].

\subsection{Assessment of OH\&S concept w.r.t Safety}

\section{Attitude and Behavior of Workers and \\ Management}

Poor attitude and indiscipline at construction site is another reason for accidents. Poor safety attitude of workers is determined by their cultural influences, lack of proper education, low maturity levels, personal priorities and attitudinal problems such as ego and jealousy. Refusal to get integrated in a group due to any of above problems can cause misunderstanding and confusion among the group and can result in accident.

A model on safety planning and control relates the failures to human error which had a modest contribution to ensure respect for the boundaries of safety work [69]. There is generally a high and reliable level in safety management of large projects while in small projects, the safety level is generally inconsistent and low [15]. Main causes of construction accidents are found to be negligence of workers, not following work procedures, work at height, inadequate safety devices on equipment, unprofessional site management, severe work conditions and operations, insufficient experience and skill level of workers, improper use of PPE and workers poor approach about safety [1] [59].

Organizational factors are the major drivers for human behavior and safe work practices on construction sites. A long-term goal is necessary to develop effective interventions to reduce the incidence and severity of injury suffered by construction workers [8].

\subsection{Assessment of OH\&S concept w.r.t Critical}

\section{Factors}

Contractors or management need to give a proper attention on the important factors and make dynamic efforts to reduce accidents on site [9] [21]. There may be some variance in risk factors depending upon severity of the injury, type of accidents, volume and size of construction site, type of construction industry, nature of work, schedule of project, working shifts, climatic conditions, location, status of personal protective equipment etc. [53][64][60]. Factors like unscheduled work timings, working beyond ones natural capacity also have a very negative consequence on work safety [19].

\subsection{Assessment of $\mathrm{OH} \& S$ concept w.r.t Safety}

\section{Training and Training Modules}

In general, there exists insufficient communication regarding safety procedures, hazard identification and site specific conditions on construction sites. According to the occupational safety and health administration (OSHA), employers are responsible for providing safety training in the language and vocabulary the workers can understand.

Reasonable improvements in safety practices can be achieved by providing extensive training and technical support to the employers and their employees. It will be difficult to implement changes which affect cost, and the changes that are anticipated to affect the quality of work [4]. Training plays an important part and has a positive impact on safety administration [33]. It is critical to apply and implement relevant $\mathrm{H} \& \mathrm{~S}$ practices and impart effective training so that all workers involved in the project recognize and follow the regulations during work [10] [12] [31]. Provision of a community service with regional $\mathrm{OH}$ models along with training, lower the insurance premiums for the employer.

The findings of a research work with BIM (Building Information Model) features which is enabled with 3D visualization emphasized that the training modules be 
developed in different languages and should be specific for specific projects[7].

\subsection{Assessment of $\mathrm{OH} \& S$ concept w.r.t Health and}

Safety Management practices and sustainability of construction:

Improvement of construction process and sustainability depends considerably on the performance of health and safety $(H \& S)$. So in recent times, the clients, project managers, contractors, strive to improve health and safety practices in the project. Safety system depends very much on the attitude of management and workers towards safety regulations and effective enforcement of safety practices [9].

An effective implementation includes procurement of proper personal protective equipment, maintenance of accident records, root cause analysis, follow up of action plan, regular safety meetings, update the workers with safety trainings etc. Recruiting competent staff to accomplish target safety standards is also very critical [14][56].

Effective implementation of OHS plans on project sites support the construction workers not to be vulnerable on the project sites [68] [50]. Management strategy to link contractor's safety performance to accident insurance cost can provide a good incentive to improve safety standards [3]. Radical progress in OHS is required since due importance is not given and there is dearth of basic safety management approach [57]. It is also necessary to have state of the art methods to sustain the results [16].

It is very important in a construction project that better awareness and indulgence by all levels in health and safety issues is to be encouraged [41]. Absence of appropriate, robust and sustainable legislation for health and safety to administer construction site operations may lead to many complications [40]. Therefore, proper initiatives, plans and policies should be developed to mitigate any issues, which may comprise thorough preparation and scheduling of project, space constraints management, timely review of project, proficient harmonization of personnel, site and materials etc. [36].

There may be adverse effect on economic development of countries throughout the world if quality of parameters and regulations in construction industry are compromised [29]. Perception and understanding of risk factors, prevention of extra working hours, providing suitable personal protective equipment, imparting training etc. are efficient and proven tools which help to decrease prevalence of occupational injuries [44]. General $\mathrm{OH} \& \mathrm{~S}$ administration performance depends on appropriate assessment of safety practices and endorsement for further upgrading and regularization of system [26][58].

Measures of safety performance and lagging indicators like injury rate can provide suitable levels of safety performance [34][35]. Leading indicator data generated from these systems can be processed and analyzed to identify hazardous proximity situations and incidents on construction sites [22].

\subsection{Assessment of OH\&S concept w.r.t Work}

\section{Related hazards and Diseases}

There are different types of health hazards in construction industry to which workers are exposed. The exposure differs from site to site. Various conditions of the hazards can be categorized as:

i) Physical : Working conditions like severe heat, humidity or extreme cold, windy, storms, foggy, snowy, rainy weather, exposure to ultra violet radiations from direct sunlight and electric arc welding etc

ii) Chemical: These include contaminated atmosphere like dust, vapors or gases, mists, fumes etc.

iii) Biological: These are associated with working with animals, people, or infectious plant materials. Work in schools, day care facilities, colleges and universities, hospitals, laboratories, emergency response, nursing homes, outdoor occupations, etc. may expose you to biological hazards.

iv) Social: Constant changes in project sites, working on sites away from family and locality, intermittent employment like lay-off \& lay-in etc.

Occupational injuries are influenced by habits like smoking, sleep syndrome, addiction to drugs and alcohol, some debilities etc. [13]. Heavy work load, limited control and limited social support are some of the other factors associated with increased stress.

Musculoskeletal disorders (MSD) by age and gender are identified as high-risk disorders. Construction industry is found to be one of the top ten high risk industries w.r.t. the occurrence of Musculoskeletal Disorders [27]. In a study it is observed that eye diseases are the most common form of disease in construction industries in Egypt at 23.6\%, followed by respiratory problems $(11.5 \%)$, heart related problems $(7.2 \%)$ etc. [2].

\section{Assessment of OH\&S concept w.r.t Post- construction stage (Commissioning, startup and handing over)}

In post construction and commissioning stage, the contractor will be in a withdrawal mood and shifts his core team to a different assignment elsewhere. At the same time, the owner might have not taken complete control of activities and employs new employees who do not have enough experience or awareness of occupational health and safety. Therefore, the focus on $\mathrm{OH} \& \mathrm{~S}$ will be reduced, resulting in incidents and fatalities. There was an unfortunate incident reported by Pillsbury Winthrop Shaw Pittman LLP on February 25, 2010 during the commissioning stage. In an explosion on February 7, 2010 at Kleen energy plant in Middletown, Connecticut, there occurred an accident with 
six fatalities, multiple injuries, and substantial damage to the equipment of power plant which was under construction [43]. US Chemical Safety Board (CSB) declared that the accident has highlighted safety issues that are not restricted to this one accident alone but to commissioning of all other power plants.

Between $13^{\text {th }}$ June, 2012 and $17^{\text {th }}$ June 2014, during commissioning phase of Visakhapatnam Steel Plant in India, several fatal accidents occurred wherein 23 people died and many injuries occurred which include construction contractor workers, engineers and managers. In one of the ghastly accident in the history of Visakhapatnam Steel Plant (India) occurred on $13^{\text {th }}$ June 2012, 19 workers were burnt alive, and most of them are contract workers (employees of VSP, Blue Star, Dastur \& Co and SMS Siemag.). This incident occurred due to a huge explosion in the newly commissioned oxygen plant in the steel melting shop (Unit III). The explosion happened during trial run of the oxygen plant.

An accident, in which six workers received burn injuries, occurred on $14^{\text {th }}$ May 2014 at the Kudankulam Nuclear Power Plant, Tamilnadu, South India during its last phase of commissioning (The Indian express on $8^{\text {th }}$ May 2014).

These incidents show that startup and commissioning stage had an inherent risk. It's not easy to squeeze startup and commissioning during normal operations. Without a proven process in place, it puts entire operation and construction team at risk both financially and physically.

\section{CONCLUSIONS}

1. The concept of occupational health and safety is not only applicable to the construction phase but also equally applicable to both pre-construction and postconstruction phases.

2. The application of $\mathrm{OH} \& \mathrm{~S}$ in various activities of preconstruction stage i.e., inception and feasibility study, design, tendering and selection of suitable materials etc. will lead to the development of a frame work for an effective implementation of $\mathrm{OH} \& \mathrm{~S}$ practice during the construction and post-construction stages.

3. A qualitative occupational risk assessment model for a systematic assessment of risk during construction phases can be developed using the possibility and severity factors along with safety barriers related to work accidents.

4. Safety culture which is a product of individual and group values, attitudes, compliance to behavioral patterns etc. and the safety climate represented by workers' involvement in safety education and commitment of management has received considerable importance in the recent past in $\mathrm{OH} \& \mathrm{~S}$ management in construction activities.

5. A knowledge based system with respect to the construction health and safety and a competent assessment enable the development of a tool which can effectively support the client/owner during the selection of H\&S personnel.
6. It is the responsibility of employers to make sure that safety trainings are imparted in local language and terminology that is clearly understandable to workers. Professional employers can make a marked progress in safety practices by providing motivation, suitable training and technical expertise.

7. Factors like detailed project scheduling, space management, effective constructability review etc. can improve the health and safety strategy.

8. The reduced focuse on $\mathrm{OH} \& \mathrm{~S}$ during the postconstruction and commissioning stage may result in fatal accidents. These accidents may be due to the withdrawal moods the contractors and insufficient control of the owners on the project.

\section{REFERENCES}

[1] Abdul Rahim Abdul Hamid, MuhdZaimi Abid Majid, Bachan Singh (2008), Causes of accidents at construction sites, Malaysian Journal of Civil Engineering 20(2): $242-259$.

[2] AlazabR.M.A( 2004 ), Work-related diseases and occupational injuries among workers in the construction industry, Afr Newslett on Occup Health and Safety 2004;14:37-42.

[3] Amr A.G. Hassanein and Ragaa S. Hanna (2007), Safety Programs in Large-Size Construction Firms Operating in Egypt, The American society of safety engineers spring 2007 (Journal of SH\&E Research) Vol. 4, Num. 1.

[4] Barbara. L.Materna, DavidHarrington, Peter scholz,SusanF.Payne,Harrison.A.Stubbs, KarenHipking, EmilyMerideth,Luzkirsch,GeoffreyLomax,Patriciacoyle ,andConnieuratsu (2002) , Results of an intervention to improve lead safety among painting contractors and their employees, American journal of industrial medicine 41:119-130.

[5] BehzadEsmaeili, S.M, and Matthew R. Hallowell (2012), Diffusion of Safety Innovations in the Construction Industry, DOI: 10.1061/ (ASCE) CO.1943-7862.0000499. (C) 2012 American Society of Civil Engineers.

[6] Biggs H. C., D. P. Dingsdag, P. J. Kirk1, \& D. Cipolla (2009), Safety culture research, lead indicators, and the development of safety effectiveness indicators in the construction sector, 5th International Conference on Knowledge Technology and Society, 30 January - 1 February 2009.

[7] Caroline Clevengeri, Carla Lopezdel Puerto, and Scott Glick (2014), Developing a BIM-enabled Bilingual Safety Training Module for the Construction Industry, Construction Research Congress 2014 @ASCE 2014.

[8] Carla Lopez del Puerto, David Gilkey (2014), Injuries Among Construction Workers: An Exploratory Study, 50th ASC Annual International Conference Proceedings (2014).

[9] Chia-Kuang Lee, Yumin Jaafar (2012), Prioritization of Factors Influencing Safety Performance on Construction Sites: A Study Based on Grade Seven (G7)Main Contractors' Perspective, DOI:10.7763/IPEDR.2012.V57.2. 
[10] ChengChing-Wu , Sou-SenLeu , Chen-Chung Lin , Chihhao Fan (2010), Characteristic analysis of occupational accidents at small construction enterprises, Safety Science 48 (2010) 698-707

[11] Chia-Fen Chia, Tin-Chang Changa, Hsin-I Tingb(2005), Accident patterns and prevention measures for fatal occupational falls in the construction industry, Applied Ergonomics 36 (2005) 391-400.

[12] Chiocha (2011), Health and safety in the Malawian construction industry, Acta Structilia 2011:18(1).

[13] Chau N, Mur JM, Benamghar L, Siegfried C, Dangelzer JL, Français M, Jacquin R, Sourdot A (2004), Relationships between certain individual characteristics and occupational injuries for various jobs in the construction industry: a case-control study, American journal of industrial medician -2004 Jan :45(1) :84-92.

[14] Tam a C.M, S.X. Zenga,b, Z.M. Deng (2004), Identifying elements of poor construction safety management in China, Safety Science 42 (2004) 569586.

[15]Chehassan CR (2007), Perception of building construction workers towards safety, health and environment, Journal of engineering science and technology Vol.2. No 3 (2007) 271-279.

[16]David Walters (2009), The role of worker representation and construction in managing health and safety in the construction industry, , GB.298/STM/1/1, ILO's Governing Body, 2008-2009 biennium.

[17] David P. Gilkey ; Carla Lopez del Puerto ; Thomas Keefe ; Philip Bigelow ; Robert Herron ;John Rosecrance ; and Peter Chen( 2012), Comparative Analysis of Safety Culture Perceptions among Home Safe Managers and Workers in Residential Construction, DOI: 10.1061/(ASCE)CO.1943-7862.0000519. (C) 2012, American Society of Civil Engineers.

[18]Dolores. M, M Carmen, Alistair Gibb (2010), Prevention through design: The effect of European directives on construction workplace accidents, Safety science, Volume 48, issue 2, February 2010, Page 248258.

[19] Dong X (2005), Long work hours ,work scheduling and work-related injuries among construction workers in the United States, Scandinavian journal of work, environment and health 2005 Oct: 31(5):329- 25.

[20] Dongping Fang, Haojie Wu (2013), Development of a Safety Culture Interaction (SCI) model for construction projects, Safety Science 57 (2013) 138-149.

[21]Edwin Sawacha (1999), Factors affecting safety performance on construction sites, International Journal of Project Management Vol. 17, No. 5, pp. 309-315, 1999.

[22] Eric D. Marks1, Jeremy E. Wetherford1, *Dr. Jochen Teizer1, and Dr. Nobuyoshi Yabuki (2013), Potential of leading indicator data collection and analysis for proximity detection and alert technology in construction, ISARC 2013 Paper-281 (2013).

[23] Global Construction 2020 report published by Global Construction Perspectives and Oxford Economics.Broadwall House,21 Boradwall, London,SEI PPI,UK
[24] Hao Yu (2009), A Knowledge based system for construction health and safety comperence assessment, A thesis submitted in partial fulfillment of the requirements of the University of Wolverhampton for the degree of Doctor of Philosophy January 2009.

[25] HasanAlasamri, Malcolm T. Chrisp and Graeme Bowles (2012), A Frame work for enhancing and improving the safety culture on Saudi construction sites, 28th Annual ARCOM Conference, 3-5 September2012, Edinburgh, UK, Association of Researchers in Construction Management, 475-485.

[26] Haluk Çeçen and Begüm Sertye GilJ GJk (2013), A Fall Protection System for High-Rise Construction, Journal of Engineering Volume 2013, Article ID 239746, 5 pages http://dx.doi.org/10.1155/2013/239746.

[27] How-Ranguo, Ya-Ching Chang, Wen-Yuyeh, Chun-Wan Chen and Yueliang L.Gvo (2004), Prevalence of Muculoskeletal disorder among workers in Taiwan : A Nationwide study, Journal Occupational health 2004:46:26-36.

[28] Hulya Cakan (2012), Analysis and modeling of roofer and steel worker fall accidents, "Analysis and modeling of roofer and steel worker fall accidents" (2012).Wayne State University Dissertations. Paper 498

[29] Ikechukwu A (2012), Effective Regulation and Level of Awareness: An Exposé of the Nigeria's Construction Industry,Open Journal of Safety Science and Technology, 2012, 2, 140-146.

[30] Imriyas Kamardeen.(2005), Web-based Safety Knowledge Management System for Builders: A Conceptual Framework, Imriyas Kamardeen, Faculty of the Built Environment, University of New South Wales, Australia.

[31] Jantanee Dumrak, Sherif Mustafa, Imriyas Kamardeen, Raufdeen Rameezdeen (2013), Factors Associated with the Severity of Construction Accidents: The Case of South Australia, Dumrak, J et al (2013) 'Factors associated with the severity of construction accidents: The Case of South Australia', Australasian Journal of Construction Economics and Building, 13 (4) 32-49.

[32] Jennifer Mary Campbell (2008), Safety Hazard and Risk Identification and Management In Infrastructure Management, Doctor of Philosophy The University of Edinburgh School of Engineering and Electronics May 2008.

[33] Jimmie Hinze (2003), Safety training practices for U.S. Construction workers, ISBN 1-886431-09-4. Published: 14th May, 2003. Special Issue article.

[34] Jimmie Hinze, Samuel Thurman, Andrew Wehle (2013), Leading indicators of construction safety performance, Safety Science 51 (2013) 23-28.

[35] Jimmie Hinze (2013), Construction-Safety Best Practices and Relationships to Safety Performance, Journal of construction engineering management .2013139. DOI: 10.101061/ (ASCE) CO.19437862.0000751@2013.

[36] John P. Spillane,Lukumon O. Oyedele1, Jason Von Meding1, Ashwini Konanahalli1, Babatunde E. Jaiyeoba and Iyabo K. Tijani ( 2011).Confined site construction:A qualitative investigation of critical 
issues affecting management of health and safety. Journal of Civil Engineering and Construction Technology Vol. 2(7), pp. 138-146, July 2011, Jcect ISSN 2141-2634 (C2011Academic Journals .

[37] John Smallwood and Danie Venter (2002), The influence of project managers on construction health and safety in South Africa, The Australian journal of construction economics and building Vol.2 No.1 (2002).

[38] John Smallwood and Theo Haupt (2005), the need for construction health and safety (H\&S) and the Construction Regulations: engineers' perceptions, Journal of the South African institution of civil engineering. Vol 47 No 2 2005, Pages 2-8, Paper 581.

[39] Kanchana Priyadarshani, Goyani Karunasena and SajanJayasuriya (2013), Construction safety assessment framework for developing countries: A case study of Srilanka, Journal of construction in developing countries 18(1),33-51,2013.

[40] Laryea.S (2010), Health and safety on construction sites in Ghana, The construction, building and real estate research conference of the royal institution of chartered surveyors, Held at Dauphire University ,paris,2-3 September 2010, ISBN-978-1-84219-619-9.

[41]Leanne Hunter (2009), Manual Handling in the Irish Construction Industry: Summary Report, (ERG/09/21), Health \& safety laboratory -ERG/09/2009.

[42]Lynette Sperling, Michael B. Charles, Rachel Ryan, Kerry Brown (2008), Driving Safety: Enhancing Communication Between Clients, Constructors and Designers, Third International Conference of the Cooperative Research Centre (CRC) for Construction Innovation - Clients Driving Innovation: Benefiting from Innovation, pages pp. 1-15, Gold Coast, (2008) Australia.

[43] Mark L. Farly (2010) CSBcautions on hazards associated with commissioning of natural gas power plants.Pillsbury Winthrop showpittman LLP.

[44] Mesafint Molla Adane, Kassahun Alemu Gelaye, Getahun Kebede Beyera, Hardeep Rai Sharma and Walelegn Worku Yalew(2013), Occupational Injuries Among Building Construction Workers in Gondar City, Ethiopia, Occupational medicine \& health affairs. ISSN 2329-6879. OMHA, an open access journal 2013.

[45] Michael Toole. T., John Gambatese (2008), the Trajectories of Prevention through Design in Construction, Journal of Safety Research 39 (2008) 225-230.

[46] Napsiah Mohamad Saifullah and Faridah Ismail (2011), Integration of Occupational Safety and Health during Preconstruction Stage in Malaysia, Procedia - Social and Behavioral Sciences 35 (2012) 603 - 610.

[47] Nii Amponsah Ankrah (2007), an investigation into the impact of culture on construction project performance, A thesis submitted in partial fulfillment of the requirements of the University of Wolverhampton for the degree of Doctor of Philosophy (PhD) June 2007.

[48] Nilesh D.Chinchore and Pranay R.Khare (2014). Planning and selection of heavy construction equipment in civil engineering, Int. journal of engineering research and applications, ISSN: 2248-9622, vol.4, issue 12(part 1), December 2014,pp-29-31.

[49] Nongiba A.Kheni (2010), Health and Safety Management within Small- and Medium-Sized Enterprises „SMEs in Developing Countries: Study of Contextual Influences, Journal of construction engineering and management -2010.136:1104-1115

[50] Okeola.O.G (2009), Occupational health and safety (OHS) assessment in the construction industry, 1st Annual Civil Engineering Conference University of Ilorin, Nigeria, 26-28 August 2009.

[51] Okolie, K. C, Okoye, P.U. (2012), Assessment of National Culture Dimensions and Construction Health and Safety Climate in Nigeria, Science Journal of Environmental Engineering Research ISSN: 22767495(2012).

[52] Patrick Manu1, Nii Ankrah, David Proverbs and Subashini Suresh (2010), the contribution of construction project features to accident causation and health and safety risk: A conceptual model, 26th Annual ARCOM Conference, 6-8 September 2010, Leeds, UK, Association of Researchers in Construction Management, 261-269.

[53] Peter Anthony Kines (2002), Male Occupational Falls From Heights In-depth Analyses, SimoSalminen, Finnish Institute of Occupational Health. - November 2002.

[54] Pinto, Abel, Ribeiro, Rita A, Nunes, Isabel L (2007), Qualitative Occupational Risk Assessment model - an introduction, this work was funded by the Portuguese Foundation for Science and Technology, Scholarship No. SFRH/BD/39610/ 2007.

[55] Ploypailin Pungvongsanuraks and Thanwadee Chinda (2010), Investigation of safety performance of management and workers in Thai construction industry, Suranaree J. Sci. Technol. Vol. 17 No. 2; April - June 2010.

[56]Rafiq M. Choudhry (2012), Safety Management Practices in the Construction Industry of Pakistan, Third International Conference on Construction in Developing Countries (ICCIDC-III)“Advancing Civil, Architectural and Construction Engineering \& Management'July 4-6, 2012, Bangkok, Thailand.

[57] Rizwan U. Farooqui (2008), Safety Performance in Construction Industry of Pakistan, First International Conference on Construction In Developing Countries (ICCIDC-I) "Advancing and Integrating Construction Education, Research \& Practice" August 4-5, 2008, Karachi,, Pakistan.

[58]RizaYosia Sunindijo, Patrick X.W. Zou (2009), Investigating the potential relationships between project manager skills and project safety performance, http://unsworks.unsw.edu.au/fapi/datastream/unsworks: 11222/SOURCE01.

[59] Ruoyu Jin and Qian Chen (2013), Safety culture Effects of Environment, Behavior \& Person, Professional Safety MAY 2013 www.asse.org

[60] Sai X. Zeng, Chun M. Tam , Vivian W. Y. Tam( 2010), Integrating Safety, Environmental and Quality Risks for Project Management Using a FMEA Method, ISSN 
1392 - 2785 Inzinerine Ekonomika-Engineering Economics 2010, 21(1).

[61] Sam Wamuziri (2008), Improving safety performance in construction through cultural change, 24th Annual ARCOM Conference, 1-3 September 2008, Cardiff, UK, Association of Researchers in Construction Management, 1103-1111.

[62] Saud Al-Anbari, Khalina A, Ali Alnuaimi, Normariah A and Yahya A, (2013), Safety and health risk assessment at Oman building construction project, IJRET: International Journal of Research in Engineering and Technology eISSN: 2319-1163 | pISSN: 2321-7308.

[63] Smallwood. J. J (2002), The Influence of health and safety $(H \& S)$ culture on $H \& S$ performance, $18^{\text {th }}$ Annual ARCOM conference,2-4 September 2002. Association of research in construction management, Vol -1,21726.

[64] Sophi Hide et al (2003), Causal factors in construction accidents, prepared by Loughborough University and UMIST for the Health and Safety Executive 2003.

[65] Steven Hecker, Linda Goldenhar (2013), Understanding Safety Culture and Safety Climate in Construction: Existing Evidence and a Path Forward, Literature Review Summary for Safety Culture/Climate Workshop June 11-12, 2013 Washington, DC.

[66] Suchismita Bhattacharjee, Somik Ghosh (2011), Safety Improvement Approaches in Construction Industry: A Review and Future Directions, 47th ASC Annual International Conference Proceedings (2011).

[67] Thanwadee Chinda and Sherif Mohamed (2008), Structural equation model of construction safety culture, Engineering, Construction and Architectural Management Vol. 15 No. 2, 2008 pp. 114-131.

[68] Tascisio A. Saurin,Carlos T. Formoso, and Fabricio B, Cambraia (2004), A human error perspective of safety planning and control, www.iglc2004.dk/13074_061.

[69] Tarcisio Abreu Saurin, Carlos Torres Formoso and Fabricio Borges Cambraia (2005), Analysis of a safety planning and control model from the human error perspective, Engineering, Construction and Architectural Management Vol. 12 No. 3, 2005 pp. 283298.

[70] Tomasz stepien (2014), Identification of factors determining accident rate in construction industry.Technical transactions Czasopismotechniczne Civil Engineering budownictwo 1-B/2014.

[71] Thomas S. Ng (2005), Building and environment A Frame work for evaluating the safety performance of construction contractors, Building and environment 40(10): pp-1347-1355(2005).

[72] Xinyu Huang (2003), The Owner's role in construction industry, A Dissertation presented to the Graduate school of the University of Florida in partial fulfillments for the degree of Doctor of Philosophy University of Florida 2003.

[73]Zahra Jabbarani Torghabeh (2012), Designing for construction worker's safety, International Journal of Advances in Engineering \& Technology, Sept 2012. CIJAET ISSN: 2231-1963.
[74] Wadsworth Emma J K (2009), Safety culture, advice and performance, Policy and Practice in Health and Safety 07.12009 @ IOSH Services Limited. 